\title{
GLOBAL BODY POSTURE EVALUATION IN PATIENTS WITH TEMPOROMANDIBULAR JOINT DISORDER
}

\author{
Eliza Tiemi Saito, Paula Marie Hanai Akashi, Isabel de Camargo Neves Sacco
}

doi: $10.1590 / \mathbf{S 1 8 0 7 - 5 9 3 2 2 0 0 9 0 0 0 1 0 0 0 0 7}$

Saito ET, Akashi PMH, Sacco ICN. Global body posture evaluation in patients with temporomandibular joint disorder. Clinics. 2009;64(1):35-9.

\begin{abstract}
AIM: To identify the relationship between anterior disc displacement and global posture (plantar arches, lower limbs, shoulder and pelvic girdle, vertebral spine, head and mandibles). Common signs and symptoms of anterior disc displacement were also identified.

INTRODUCTION: Global posture deviations cause body adaptation and realignment, which may interfere with the organization and function of the temporomandibular joint.

METHODS: Global posture evaluation was performed in a group of 10 female patients (20 to 30 years of age) with temporomandibular joint disc displacement and in a control group of 16 healthy female volunteers matched for age, weight and height. Anterior disc displacement signs, symptoms and the presence of parafunctional habits were also identified through interview.

RESULTS: Patients with disc displacement showed a higher incidence of pain in the temporomandibular joint area, but there were no differences in parafunctional habits between the groups. In the disc displacement group, postural deviations were found in the pelvis (posterior rotation), lumbar spine (hyperlordosis), thoracic spine (rectification), head (deviation to the right) and mandibles (deviation to the left with open mouth). There were no differences in the longitudinal plantar arches between the groups.

CONCLUSION: Our results suggest a close relationship between body posture and temporomandibular disorder, though it is not possible to determine whether postural deviations are the cause or the result of the disorder. Hence, postural evaluation could be an important component in the overall approach to providing accurate prevention and treatment in the management of patients with temporomandibular disorder.
\end{abstract}

KEYWORDS: Temporomandibular Joint; Temporomandibular Disorder; Biomechanics; Posture; Physical Therapy.

\section{INTRODUCTION}

The temporomandibular joint (TMJ) is the most regularly used joint in the human body. It opens and closes about 1500 to 2000 times a day and is instrumental in several functional movements such as chewing, breathing and pronunciation. ${ }^{1}$ Because the TMJ is a very regularly used joint, its bone, muscle or cartilage may deteriorate over time, leading to disorders of the TMJ. Temporomandibular disorder (TMD) may lead to adaptations in certain body structures to minimize a patient's pain or discomfort, and also to

Departamento de Fonoaudiologia, Fisioterapia e Terapia Ocupacional, Faculdade de Medicina, Universidade de São Paulo - São Paulo/SP, Brazil. Email: elizatiemi@gmail.com

Tel.: 55113091.7459

Received for publication on July 1, 2008

Accepted for publication on September 25, 2008 reconfigure musculoskeletal stress zones. These adaptations often lead to deviations in normal body posture, which includes changes in the longitudinal plantar arches. ${ }^{2}$

Epidemiological studies of TMD show that 5 to $6 \%$ of the world population will suffer a painful experience involving the TMJ at some point during their life, ${ }^{3}$ and that around 8.5 million Brazilians will require some kind of intervention for TMD. ${ }^{4}$

The biomechanical complexity of body posture derives from the functional integration of several body segments: when there is a change in any biomechanical subunit, a refinement of the postural control systems will necessarily occur. ${ }^{5,6}$ The muscle groups of the stomatognathic system belong to the cervical muscular chain. Considering that the musculoskeletal system is composed of several such muscular chains that are integrated with one another, any disturbance of a body segment will lead to a reorganization 
of other segments. ${ }^{7,8}$ This fine tuning of posture control leads to body segment adaptation and realignment, whether physically near to or distant from the TMJ., ${ }^{2,5,8}$ Deviations in the lower limbs can interfere with postural organization and may even impact head and neck posture. ${ }^{?}$

Valentino et al. ${ }^{10}$ have shown that the simulation of a flat foot results in increased muscular activity of the masseter and temporal muscles. When a concave foot was simulated, this activity reduced. Alteration of the longitudinal plantar arches stimulates mechanoreceptor neurons, and this readjusts head position and body center of gravity. These data reinforce the theory that a deviation in one joint unit can lead to compensation in other joints and, therefore, to an alteration of whole-body posture..$^{2,5-9}$

It is important to establish a clear relationship between poorly aligned body posture and the incidence of TMD in order to clarify if the best physical therapy treatment for TMD patients should include body posture realignment. Our goal is to minimize symptomatology and to de-emphasize postural deviations that may lead to bone and muscle system imbalance. . $^{91-14}$

Although there exist certain studies ${ }^{15-18}$ that have attempted to find a relationship between postural alterations in TMD patients, these studies did not select patients according to their specific diagnoses. Furthermore, to date, there have been no studies that investigate this relationship in a group of TMD patients composed only of women diagnosed with anterior disc displacement. Also, body deviation studies have focused only on the upper quarter of the body and have not investigated foot alignment. In one study ${ }^{10}$ that involved the foot, postural deviation was only simulated. Consequently, the researchers did not adequately represent real-world postural foot deviations, and the presence of head and neck postural problems was not assessed. In the same way, other studies ${ }^{3,11}$ did not investigate pain in parts of the body other than in the upper quarter.

The aim of this paper was to evaluate and describe the most common TMD diagnosed at the Occlusion and TMJ Service (SOA) of the Faculty of Dentistry of the University of São Paulo (FOUSP) - anterior disc displacement - and the associated postural deviations as they relate to the plantar arches, lower limbs, shoulder and pelvic girdle, vertebral spine, head and mandibles. We also aimed to identify common signs and symptoms across the entire body, through our observations of a group of women between 20 and 30 years of age, all of whom had been diagnosed with anterior disc displacement.

\section{METHODS}

Our study involved 26 volunteer women distributed across two groups: a disc displacement group (DDG) and a control group (CG). The choice of involved subjects was based on epidemiological research that showed women from 15 to 40 years of age are most often affected by TMD. ${ }^{19-20}$

The control group consisted of 16 female volunteers without a clinical diagnosis of disc displacement, aged 24.4 $\pm 2.8 \mathrm{yr}$ and of body mass $56.2 \pm 7.9 \mathrm{~kg}$. They were matched for age and weight with a disc displacement group, consisting of 10 female patients 20 to 30 years of age $(24.5 \pm 3.0 \mathrm{yr}, 55.5$ $\pm 7.4 \mathrm{~kg}$ ) who had been diagnosed with unilateral TMJ disc displacement and had presented symptoms for $40.4 \pm 41.5$ months prior to the start of our trial. The patients' disorders were clinically diagnosed by postgraduate students from Occlusion and TMJ Service (SOA) of Faculty of Dentistry of University of São Paulo (FOUSP). The diagnoses were confirmed by their professors. X-ray imaging was used to assist with diagnoses. Exclusion criteria were: any trauma history, anatomical deformities and skeletal system fractures, hormonal alterations, orthopedic or rheumatic diseases already diagnosed, three months or more into pregnancy, and no previous TMD treatment over a period of 15 days before this initial assessment. Approval was obtained from the local institutional ethics committee (protocol no. 30/05).

As part of the initial screening procedures, all subjects were interviewed regarded their parafunctional habits, signs and symptoms, and degree of pain consistent with the Visual Analog Scale. Following this initial step, an experienced physical therapist performed an independent postural body assessment by visually inspecting all the subjects. For this part of the study, the patients were asked to stand as comfortably as possible wearing bathing suits in a bipedal position with bilateral symmetric weight bearing, while looking towards the horizon. The physical therapist marked the following bone reference points using adhesive tape: lateral malleoli, heads of the fibulas, major trochanter of the femur, antero-superior and postero-superior iliac spines, coracoid processes, C7 and the inferior angle of the scapulas. The frontal anterior and posterior planes and sagittal right and left planes were evaluated. The evaluation protocol was based on Kendall ${ }^{21}$ : any changes from the standard alignment posture were considered evidence of postural deviations. Following data acquisition, an experienced physical therapist confirmed all postural classifications using digital photos. This analysis was performed using visual inspection with a digital matrix of horizontal and vertical lines, all of which passed through the bone reference markers. Footprint measurements were taken using a Harris Mat, and the characteristics of the longitudinal plantar arches were evaluated according to Cavanagh and Rodgers. ${ }^{22}$ The Cavanagh and Rodgers ${ }^{22}$ plantar arch evaluation uses the ratio between the mid-foot area and the total foot area, excluding the toe area, as measured by a digital 
planimeter. The arch is classified as follows: lower than 0.21 is considered elevated, between 0.22 and 0.26 is normal, and higher than 0.26 is designated a low arch.

Data were analyzed using descriptive statistics and were tested to compare independent group means. When comparing dichotomic categorical data, we used the nonparametric Chi-Squared and Fisher's Exact tests. For multicategory variables, we used the Mann-Whitney test. We chose an $\alpha$ of 0.05 .

\section{RESULTS}

The disc displacement group showed reported pain more often, but only the presence of local TMJ pain was significantly different in comparison with the CG $(p=0.006)$ (Table 1). There were no statistical differences between groups $(\mathrm{p}>0.05)$ in parafunctional habits (biting tongue, cheeks or lips, chewing gum, biting objects such as pen caps, holding one's head with the hands, chewing only on one side of the mouth).

The footprint measurements that characterized patients' longitudinal plantar arches were not different between groups

Table 1 - Percentage of subjects reporting body pain in the two groups

\begin{tabular}{lcc}
\hline Location of pain $(\%)$ & CG & DDG \\
\hline Head & 0 & 20 \\
TMJ $(p=0.006)$ & $0^{*}$ & $40^{*}$ \\
Neck & 12 & 20 \\
Shoulder & 0 & 20 \\
Trapezius muscle & 37 & 50 \\
Rhomboid major muscle & 6 & 20 \\
Lumbar spine & 18 & 40 \\
Inferior limbs & 12 & 30 \\
Other & 0 & 30 \\
\hline
\end{tabular}

$(* p<0.05)$

Table 2 - Postural assessments of the pelvis in the sagittal plane and of the head in the frontal plane

\begin{tabular}{llccc}
\hline & & CG & DDG & $p$ \\
\hline Pelvis $(\%)^{*}$ & Aligned & 93.7 & 40 & 0.02 \\
& Anterior rotation & 0 & 10 & \\
& Posterior rotation & 6.3 & 50 & \\
Head $(\%)^{*}$ & Aligned & 87.5 & 30 & 0.002 \\
& Deviation to the R & 12.5 & 50 & \\
& Deviation to the L & 0 & 20 & \\
\hline
\end{tabular}

$(* p<0.05)$
Table 3 - Postural assessments of the lumbar and thoracic spine

\begin{tabular}{lcccccc}
\hline & \multicolumn{3}{c}{ Lumbar spine $(\%) *$} & \multicolumn{3}{c}{ Thoracic spine $(\%) *$} \\
\cline { 2 - 7 } Group & Aligned & Lordosis & Rectified & Aligned & Kyphosis & Rectified \\
\hline CG & 62.5 & 37.5 & 0 & 62.5 & 0 & 37.5 \\
DDG & 10 & 90 & 0 & 10 & 20 & 70 \\
$p$ & 0.03 & & & 0.03 & & \\
\hline
\end{tabular}

$(* p<0.05)$

$(p>0.05)$. Both groups presented normal longitudinal plantar arches, according to Cavanagh and Rodgers ${ }^{18}$ (CG $=56.25 \%, \mathrm{DDG}=50 \%$; low $\operatorname{arch}-\mathrm{CG}=18.75 \%$, DDG $=$ $20 \%$; high arch $-\mathrm{CG}=25 \%$, DDG $=30 \%$ ).

Pelvis, head and spine-based postural assessments in the frontal and sagittal planes were significantly different between the groups (Tables 2 and 3). Finally, the postural assessment of the mandibles in the frontal plane showed a higher incidence of deviation to the left side with an open mouth in the DDG $(40 \%)(p=0.03)$ (Table 4). No other postural deviations were observed in other body segments.

\section{DISCUSSION}

The main purpose of our study was to evaluate and associate the presence of anterior disc displacement with postural deviations across the entire body. The hypothesis of a functional relationship between the stomatognathic system and other body regions remains controversial, especially for body areas that are distant from the TMJ. ${ }^{5,9-13}$

Other studies have attempted to identify a relationship between postural alterations in TMD patients, but none of these trials have specifically focused on women. Besides, many studies have only investigated the upper quarter of the body, either to assess postural alignment or to identify pain locations.

Our results demonstrated that important postural alterations are exhibited by subjects with anterior disc displacement, and these postural deviations can be associated with TMD.

Considering that pain levels were similar across both groups, except for local TMJ pain that was more frequently reported by the DDG subjects, we suggest that there exists no relationship between body pain and TMD.

Although parafunctional habits were more often present in the DDG, there were no statistical differences between the groups. Consistent with previous studies ${ }^{4,23}$, our data show the importance of carefully investigating the real influence of parafunctional habits on TMD.

The evaluation of patients' longitudinal plantar arches 
Table 4 - Postural assessments of the mandibles in the frontal plane, with mouth open and closed

\begin{tabular}{lccccc}
\hline & \multicolumn{4}{c}{ Mandibles (\%) * } \\
\cline { 2 - 6 } Group & Aligned & Closed + deviation to R & Closed + deviation to L & Opened + deviation to R & Opened + deviation to L \\
\hline CG & 81.2 & 0 & 0 & 12.5 & 6.3 \\
DDG & 40 & 10 & 0 & 10 & 40 \\
$p$ & 0.03 & & & \\
\hline
\end{tabular}

$\left({ }^{*} p<0.05\right)$

showed no statistically significant difference between CG and DDG. Our results showed similarities in longitudinal plantar arch anthropometry between the groups, suggesting no relationship between TMD and this characteristic. This result contrasts with that of another study ${ }^{10}$ in which flat foot simulation induced an increase in temporal and masseter EMG activity on the side of the simulation. This could cause postural deviations in cervical and head positions and problems at the TMJ. Such a hypothesis regarding the presence of head and neck postural deviations was not confirmed, and no postural evaluations were conducted in that study.

Postural assessments in our study confirmed the findings of previous studies ${ }^{15-18}$, which revealed DDG-related changes in body posture, particularly in the pelvic position, lumbar and thoracic spines, head and mandibles. These deviations seem to confirm the relationship between the position of the TMJ and other body parts. Our results support the theory that a deviation in one joint subunit may lead to compensations in other joints ${ }^{2,5-9}$.However, these results must be interpreted with caution because it is not possible to conclude whether TMD is a cause or a result of body posture deviations.

Certain limitations were evident in this investigation.
First, the clinical diagnoses may have included a limited number of false-positive disc displacement diagnoses..$^{24,25} \mathrm{In}$ addition, and because this was a transverse study, subjects were evaluated only once, so the data do not take into account individual variation over time.

\section{CONCLUSION}

Due to the high incidence of TMD across the population, investigating the relationship between this condition and global posture is extremely important. Our data showed significant DDG-related deviations in the pelvis, lumbar and thoracic spines, head and mandibles. Although it is not possible to positively state a cause-effect relationship, our data at least verify the mutual existence of global body posture deviations and TMD.

We conclude that the postural evaluation of TMD patients is clearly important as a global approach to provide accurate prevention and treatment. Such evaluations can help physicians to achieve more precise diagnoses and select the best possible functional rehabilitation techniques. In the case of TMD patients, it is essential to achieve a better level of interaction among the different therapeutic subspecialties.

\section{REFERENCES}

1. Hoppenfeld S. Propedêutica Ortopédica: coluna e extremidades. São Paulo: Atheneu, 2001.

2. Marzola FT. O papel da fisioterapia nas disfunções da articulação têmporo-mandibular: uma revisão da literatura. [Monografia] São Paulo (SP): Universidade de São Paulo, 1999.

3. Svensson P, Graven-Nielsen T. Craniofacial muscle pain: review of mechanisms and clinical manifestations. J Orofac Pain. 2001;15:11745 .

4. Oliveira W. Disfunções Temporomandibulares. v.6, São Paulo: Artes Médicas, série EAP, APCD, 2002.

5. Farah EA, Tanaka C. Postura e mobilidade da coluna cervical e do tronco em portadores de alterações miofuncionais orais. Revista da Associação Paulista de Cirurgiões Dentistas. 1997:51:171-75.

6. Bricot B. Posturologia. São Paulo: Ícone, 1999.
7. Souchard PE. Reeducação Postural Global. São Paulo: Ícone, 1990.

8. Rocabado M. Cabeza e Cuello - Tratamiento Articular. Buenos Aires: Intermédica, 1979.

9. Lee WY, Okeson JP, Lindroth J. The relationship between forward head posture and temporomandibular disorders. J Orofac Pain. 1995;9:1617.

10. Valentino B, Melito F, Aldi B, Valentino T. Correlation between interdental occlusal plane and plantar arches. An EMG study. Bull Group Int Rech Sci Stomatol Odontol. 2002;44:10-3.

11. Mannheimer JS, Rosenthal RM. Acute and chronic postural abnormalities as related to craniofacial pain and temporomandibular disorders. Dent Clin North Am. 1991;35:185-208.

12. Rego Farias AC, Alves VCR, Gandelman H. Estudo da relação entre a disfunção da articulação temporomandibular e as alterações posturais. Rev. Odontologia da UNICID. 2001;13:125-33. 
13. Wright EF, Domenech MA, Fischer JR. Usefulness of posture training for patients with temporomandibular disorders. JADA. 2000;131:20210.

14. McNeely ML, Armijo OS, Magee DJ. A systematic review of the effectiveness of physical therapy interventions for temporomandibular disorders. Phys Ther. 2006;86:710-25.

15. Nicolakis P, Nicolakis M, Piehslinger E, Ebenbichler G, Vachuda M, Kirtley C, et al. Relationship between craniomandibular disorders and poor posture. J Craniomand Practice. 2000;18:106-12.

16. Pedroni CR, Oliveira AS, Guaratini MI. Prevalence study of signs and symptons of temporomandibular disorders in university students. J Oral Rehabil. 2003;30:283-89.

17. Zonnenberg AJ, Van Maanen CJ, Oostendorp RA, Elvers JW. Body posture photographs as a diagnostic aid for musculoskeletal disorders related to temporomandibular disorders (TMD). Cranio. 1996;14:22532.

18. Fink M, Wahling K, Stiesch-Scholz M, Tschernitschek $\mathrm{H}$. The functional relationship between the craniomandibular syste, cervical spine, and the sacroiliac joint: a preliminary investigation. J Craniomand Practice. 2003;21:202-208.
19. Solberg WK. Disfunções e desordens temporomandibulares. $2^{a}$ ed. São Paulo: Santos; 1999.

20. Egermark I, Carlsson GE, Magnusson T. A 20-year longitudinal study of subjective symptoms of temporomandibular disorders from childhood to adulthood. Acta Odontol Scand. 2001;59:40-8.

21. Kendall FP, McCreary EK, Provance PG. Músculos: provas e funções. Manole, 1995.

22. Cavanagh P. R.; Rodgers, M. M. The Arch Index: a useful measure from footprints. J. Biomech. 1987;20:547-51.

23. Magee DJ. Avaliação Musculoesquelética. $3^{\text {a }}$ ed. São Paulo: Manole, 2002.

24. Orsini MG, Kuboki T, Terada S, Matsuka Y, Yatani H, Yamashita A Clinical predictability of temporomandibular joint disc displacement. J Dent Res. 1999;78:650-60.

25. Toginini F, Manfredini D, Montagnani G, Bosco M. Is clinical assessment valid for the diagnosis of temporomandibular joint disk displacement? Minerva Stomatol. 2004;53:439-48. 